\title{
Determination of Optimum Quantity Cost and Cycle Time Using Inventory Model with Stock Level Dependent Demand Rate and Variable Holding Cost. (A Case Study of Mantrac Ghana Limited).
}

\author{
Bernard Osei Owusu ${ }^{1}$, Anthony Kwarteng ${ }^{2}$ \\ ${ }^{1}$ The Department of Mathematics, Anglican Senior High School, Kumasi, Ghana \\ ${ }^{2}$ The Department of Engineering, Ghana Technology University College, Ghana \\ Corresponding author: Bernard Osei Owusu
}

\begin{abstract}
An inventory represents one of the most important assets that most businesses possess. The turnover of an inventory represents one of the primary sources of revenue generation and subsequent earnings for the company's shareholders/owners. However, if an inventory is not properly managed, it could adversely affect the company. This paper sought to model Mantrac Ghana Limited's inventory cost as a retroactive holding cost, so as to determine the optimal order quantity, reorder point and optimal total cost of the company. The researchers obtained data from the Inventory Department of Mantrac Ghana Limited on stock, demand and supply of Hoses covering a period of six years on monthly basis. Retroactive Holding Cost solution algorithm was used to solve the problem. To carry out the computations, the computer software, Derive 6, Minitab 16 and Matlab were used to analyze the problem. The research revealed that low quantity cost with corresponding higher cycle times results in Low Total Inventory Cost. The higher the optimum cost, the higher the Total Inventory Cost. It was also shown that the inventory of Mantrac Ghana Limited could be sustained if the stakeholders of the company adopt the Retroactive Holding Cost Model to produce the quantity Q*, of $\mathbf{4 0 9}$ units per each order within the cycle period of 0.2 year.
\end{abstract}

Keywords: Inventory, Retroactive, Optimum, Cost, Algorithm, Quantity, Demand, Supply, Mantrac.

\section{Background of the Study}

An inventory represents one of the most important assets that most businesses possess. The turnover of an inventory represents one of the primary sources of revenue generation and subsequent earnings for the company's shareholders/owners. Possessing a high amount of inventory for long periods of time is not usually good for a business because of inventory storage, obsolescence and spoilage costs. However, possessing too little inventory is not good either, because the business runs the risk of losing out on potential sales and market shares. Inventory management forecasts and strategies, such as a justin-time inventory system, can help minimize inventory costs because goods are created or received as inventory only when needed.

Inventory modeling is one of the most developed fields of operations management and much space has been devoted to this topic in the management science, operational research and practitioner oriented journals. One of the basic implicit assumptions of inventory models has been the infinite shelf life of products while in storage.
That is, a product once in stock remains unchanged and fully usable for satisfying future demand. Management scientists have been applying quantitative methods to help inventory managers to make two critical decisions: how much inventory to order, and when to order it.

With low value items, how much to order and when to order can be based on simple heuristics or rules of thumb. In traditional inventory models, the demand rate is assumed to be a given constant. Various inventory models have been developed for dealing with varying and stochastic demand. All these models implicitly assume that the demand rate is independent, i.e. an external parameter is not influenced by the internal inventory policy.

In real life, however, it is frequently observed that the demand for a particular product can indeed be influenced by internal factors such as price and availability. The change in the demand in response to inventory or marketing decisions is commonly referred to as demand elasticity. Most models that consider demand variation in response to item availability (i.e. inventory level) assume that the holding cost is constant for the entire inventory cycle. This thesis presents an inventory model with 
a stock-level dependent demand rate and a variable holding cost. In this model, the holding cost is an increasing step function of the time spent in storage. Two types of time-dependent holding cost increase functions rate considered: Retroactive increase and incremental increase. For each type, a simple algorithm that minimizes the total inventory cost (TIC) is developed for calculating the optimal order quantity and associated cycle time.

The step structure of the holding cost function may be unique since it is the representative of many real- life situations in which the storage times can be classified into different ranges, each with its distinctive holding cost. This is particularly true in the storage of deteriorating and perishable items such as food products. The longer these food products are kept in storage the more sophisticated the storage facilities and services needed, and therefore, the higher the holding cost. For example, three different holding cost rates may apply to shortterm, medium term and long term food storage.

\section{Brief History of Mantrac Ghana Limited}

Mantrac Ghana Ltd. is the sole authorized dealer for Caterpillar Products in Ghana. It provides Caterpillar machines and parts, lift trucks and warehousing equipment for a wide range of applications in the areas such as construction, agricultural and mining sectors.

They also provide generators for the oil, industrial marine, power generation, agriculture and pump applications.

The company also supplies Kenworth trucks, Ingersoll-Rand drilling equipment and Perkins engines. They provide full product support service, ranging from simple component repairs to complete rehabilitation of machines.

Besides, they distribute and support the full range of CAT construction equipment including Wheel Loaders, Skid Steer Loaders, Dump Articulated Trucks, Backhoe Loaders, Excavators, Motor Graders, Track-Type Tractors and other products.

Highly-qualified employees work through an extensive branch network that includes a head office in Accra and branches in Kumasi, Takoradi and Tarkwa.

Mantrac service centers are equipped to perform total overhauls. They also have qualified service engineers, with necessary diagnostic and repair tools that can be dispatched at any time to customers.

\section{Statement of the Problem}

The main problem facing the company is the conditional expected marginal holding cost incurred by maintaining excess inventory due to over-ordering; and the conditional expected backlogging cost incurred by not satisfying demand on time due to under ordering.
The company currently faces the potential problem of setting optimum safety stock level for an inventory-level dependent demand rate and a time dependent holding cost. The company's strategy is good for safety stock, but they may order too many quantities which will lead to increase in holding cost and the risk of losses through obsolesce or damages or they may order too small which could also increase the risk of lost sales and unsatisfied customers.

This study demonstrated the need to set up a master ordering schedule considering the imprecise nature of forecasts of future demands and the uncertain lead time of the manufacturing process.

\section{Objectives}

The objectives of the study are as follows:

to model Mantrac Ghana Limited's inventory cost as retroactive holding cost problem,

to determine optimal order quantity, reorder point and optimal total cost of Mantrac Ghana

Limited, using a Retroactive solution Algorithm.

\section{Justification}

Most companies in Ghana incur much cost as a result of keeping excess inventory in the warehouse. The operating cost of these companies keeps on increasing as the years go by. Also, some of these companies do not deliver services to their customers on time as a result of inadequate stocks hence the need for proper investigation into inventory control.

Furthermore due to unavailability of factories which produce some essential goods that consumers need, some companies (retailers and wholesalers) have their goods run out of stock thereby affecting the economic and social survival of the population who depends solely on these companies.

To solve the aforementioned problems, there is the need to use scientific approaches such as modeling inventory cost of companies as retroactive holding cost problem using a Retroactive solution Algorithm. When this is done, the operational cost of the companies would be reduced so as to maximize their returns. It may also lead to the expansion of the companies, hence creating the employment for some people in the country.

\section{Limitations to the Study}

The management of the Mantrac Ghana Limited felt reluctant to give out the data. So the researchers had to travel a long distance from Kumasi to Accra several times before the data was retrieved. The travels cost the researchers a lot of money. Besides, it was time consuming, since the researchers had to abandon their works for the sake of data and other necessary documents. 


\section{Methodology}

The problem considered in the survey was to determine the optimum quantity of goods to order, the cost and the period within which to order so as to maximize the profit.

The model was developed for the inventory system based on allowing unit holding cost values to vary across different storage period. Variable unit holding costs were considered in the model in determining the optimal inventory policy.

The holding cost per unit is assumed to be increased only when the storage time exceeds specified discrete values. In other words, the holding cost per unit time is an increasing step function of the storage time. Two types of holding cost step function are considered: Retroactive Holding Cost Model and Lot - size model. Forecast and simulation methodology were used to get the optimal solution. In retroactive increase, the unit holding cost rate of the last storage period was applied to all storage periods.

Data was obtained from the inventory department of Mantrac Ghana Limited .The following data was obtained:

- Stock list,

- Cost per unit item,

- Data on demand,

- Data on supply,

- Inventory holding cost

Mathematical software such as Derive 6, Minitab 16 and Matlab were applied to solve the equations and the algorithms involved. Materials from the internet, books on inventory from KNUST library, papers and journals on inventory were used in carrying out this project.

\section{LITERATURE REVIEW}

The development of modern inventory management principles began when Harris (1913) derived the Economic Order Quantity (EOQ) formula. EOQ assumes that demand occurs at known, constant rate and supply fulfills the replenishment order after a fixed lead time. Unfortunately, the real world is not as ideal as that. In reality, demand rate is rarely constant; hard-topredict market is common in most practical situations.

Also, unpredictable events in supply systems can cause unpredictable delays in replenishments. Moreover, in current times when outsourcing is at the centre stage, complex and longer supply chains magnify the length and variability of lead times (Welborn, 2008). Although in the early days researchers acknowledged the necessity for considering uncertainties present in the real world, the rigorous work on inventory control models with stochastic features really began in 1950s. The classic book by Hadley and Whitin (1963), comprehends the research work done in this field to that date. This fundamental research done in those early days has had a pivotal effect on the subsequent developments in the field of inventory theory.

The aim of inventory management is to minimize total operating costs while satisfying customer service requirement. In order to accomplish this objective, an optimal order policy would be determined by answering to questions such as when to order and how much to order. The operating costs taken into account, the procurement costs, the holding costs and the shortage costs which are incurred when the demand of the client cannot be satisfied (either lost sales costs or orders costs).

There exist different inventory policies namely: periodic review policy and the continuous review policy. The first policy implies that the stock level will be checked after a fixed period of time and an ordering decision will be made in order to complete the stock to an upper limit ( order up to point), if necessary. In the second inventory policy, the stock level will be monitored continuously.

Deterioration refers to decay, damage or spoilage. In respect of items of foods, films, drugs, chemicals, electronic components and radio-active substances, deterioration may happen during normal period of storage and the loss is to be taken into account where we analyze inventory systems. Dave and Patel (1983) put forward an inventory model for deteriorating items with time proportional demand, instantaneous replenishment and no shortage.

Roychowdhury and Chaudhury (1983) proposed an order level inventory model considering a finite rate of replenishment and allowing shortages. In their models Mishra (1975), Deb and Chaudhuri (1986) assumed that deterioration rate is time dependent. An extensive summary in this regard was made by Raafat (1991).

Berrotoni (1962) discussed some difficulties of fitting empirical data to mathematical distribution. It might be said that the rate of deterioration increases with age. It may be inferred that the work of Berrotoni (1962) inspired Covert and Philip (1973) to develop an inventory model for deteriorating items with Weibull distribution by using two parameters.

Mandal and Phaujdar (1989) however, assumed a production inventory model for deteriorating items with uniform rate of production and stock dependent demand. Some valuable works in this area were also done by Padmanabhan and Vrat (1995), Ray and Chaudhuri (1997), Mondal and Moiti (1999).

Today, inflation has become a permanent feature of the economy. Many researchers have shown the inflationary effect on inventory policy. 
Biermans and Thomas (1977), Buzacott (1975), Chandra and Bahner (1988), Jesse etal. (1983) and Mishra (1979) developed their inventory models assuming a constant inflation rate. An inventory model with deteriorating items under inflation when a delay in payment is permissible was analysed by Liao et al. (2000).

Bhahmbhatt (1982) developed an EOQ model under a variable inflation rate and marked-up price. Ray and Chaudhuri (1997) presented an EOQ model under inflation and time discounting allowing shortages.

In both deterministic and probabilistic inventory models of classical types; it is observed that payment is made to the supplier for goods just after getting the consignment. But actually nowadays a supplier grants some credit period to the retailer to increase the demand. In this respect Goyal (1985) just formulated an EOQ model under some conditions of permissible delay in payment.

An EOQ model for inventory control in the presence of trade credit was presented by Chung and Huang (2005). The optimal replenishment policy for EOQ models under permissible delay in payments is also discussed by Chung et al. (2002) and Cung and Huang (2003).

In recent times to make the real inventory systems more practical and realistic, Aggarwal and Jaggi (1995) extended the model with a constant deterioration rate. Hwang and Shinn (1997) determined lot-sizing policy for exponential demand when delay in payment is permissible. Shah and Shah (1998) then prepared a probabilistic inventory model with a cost in case delay in payment is permissible. After that Jamal et al. (1997) developed further following the lines of Aggarwal and Jaggi's (1995) model to take into consideration for shortage and make it more practical and acceptable in real situation.

The cost of holding an inventory is explicitly assumed to be varying over time in only few inventory models. Giri et al. (1996) developed a generalized EOQ models for deteriorating items with shortages, in which both the demand rate and holding cost are continuous functions of time. The optimal inventory policy is derived assuming a finite planning horizon and constant replenishment cycles.

Ray and Chaudhuri (1997) took the time value of money into account in analyzing an inventory system with stock-dependent demand rate and shortages. Two types of inflation rates were considered. These are internal (company) inflation and external (general economy) inflation.

There have been various models proposed for stock-level dependent inventory systems. Baker and Urban (1988) investigated a deterministic inventory system in which the demand rate depends on the inventory level described by a polynomial function. A non-linear programming algorithm was utilized to determine the optimal order size and the reorder point.

Urban (1995) investigated an inventory system in which the demand rate during stock-out periods differs from the in-stock period demand by a given amount. The demand rate depends on both the initial stock and the instantaneous stock. Urban formulated a profit-maximizing model and developed a closed-form solution.

Classical inventory models found in the existing literature generally deal with constant demand rate of the item or product. Evaluation of an inventory system with such a demand rate was first considered by F.W Harns (1915). He formulated the well-known square root formula $\sqrt{2 C 3 D / C 1}$ for economic order quantity (EOQ) of the item; where $\mathrm{C}_{1}, \mathrm{C}_{3}, \mathrm{D}$ are the holding cost, replenishment cost and demand rate, respectively. After the pioneering attempt by Harns, several other researchers have extended his constant demand rate to many other interesting and realistic situations. A description of these models can be found in Naddar or any other standard literature on the subject. As time has progressed, inventory models have been developed in which the demand rate is not required to be constant. Such studies have been undertaken by Silver and Meal, Donaldson,Silver and Datta and Pal and Mukherjee.

Very recently, it has been observed that in some situations the demand may be influenced by the on-hand inventory; that is the demand rate may go up or down if the on-hand inventory level increases or decreases. Such a situation generally arises for a consumer- goods type of inventory. In this connection, it would not be out of place to refer to the observation made by Levin et al. around it. It is a common belief that large pile of goods displayed in a supermarket will lead the customer to buy more" .Later, Silver and Peterson also noted the sales at the retail level tend to be more proportional to the inventory displayed.

A number of authors investigated inventory systems with a two-stage demand rate. Baker and Urban (1988) considered an inventory system with an initial period of level-dependent demand followed by a period of constant demand. The analysis conducted on this model imposes a terminal condition of zero inventories at the end of the order cycle. Datta and Pal (1990) analyzed an infinite time horizon deterministic inventory system without shortage, which has a level-dependent demand rate up to a certain stock level and a constant demand for the rest of the cycle. Paul et al. (1996) investigated a deterministic inventory system in which shortages are allowed and are fully back-logged. The demand is stock dependent to a certain level and thenconstant for the remaining periods. 
Hwang and Hann (2000) constructed an inventory model for an item with an inventory-level dependent demand rate and a fixed expiry date. All units that are not sold by their expiry date are regarded as useless and therefore discarded. Separable programming is utilized to determine the optimal order level and order cycle length.

Ray and Chaudhuri (1997) took the time value of money into account in analyzing an inventory system with stock-dependent demand rate and shortages.

Shao et al. (2000) determined the optimum quality target for a manufacturing process where several grades of customer specifications may be sold. Since rejected goods could be stored and sold later to another customer, variable holding costs are considered in the model.

Beltran and Krass (2002) analyzed the dynamic lot sizing problem with positive or negative demands and allowed disposal of excess inventory. Goh (1994) apparently provided the only existing inventory model in which the demand is stock dependent and the holding cost is time dependent. He considered two types of holding cost variation:(a) a nonlinear function of storage time and (b) a nonlinear function of storage level. Goh (1992) modeled a holding cost variation over time as a continuous nonlinear function, the storage time was divided into a number of distinctive periods with successively increasing holding costs. As the storage time extends to the next time period, the new holding cost can be applied either retroactively (to all storage periods) or incrementally (to new period only).

Zipkin (2000) provided a systematic discussion of inventory models with stochastic lead times. systems, parallel systems and limitedcapacity systems. Exogenous sequential systems are essentially standard inventory systems with constant lead times replaced by stochastic lead times (Kaplan, 1970).In a parallel system, an infiniteserver queue is used to model the supply process. With an unlimited capacity, the order lead times are independent and identically distributed random variables.

The aim of inventory management is to minimize total operating costs while satisfying consumer service requirements. In order to accomplish this objective, an optimal ordering policy would be determined by answering questions such as when to order and how much to order. The operating costs taken into account are the procurement costs, the holding costs and the shortage costs which are incurred when the demand of a client cannot be satisfied (either lost sales costs or backorder costs).

There exist different inventory policies which are periodic-review policy and the continuous-review policy. The first policy implies that the stock level will be checked a fixed period of time and an ordering decision will be made in order to complete to an upper limit (order up to point), if necessary .In second policy, the stock level will be monitored continuously. A fixed quantity will be ordered when the stock level reaches a reorder point. The order quantity will only be delivered after a fixed lead time and shortage can exist if the inventory is exhausted before the receipt of the order quantity. Those basic policies can be adapted to take into account special situations such as stochastic demands and lost sales or backorder.

Research on Inventory Record Inaccuracy (IRI) has been taking place since 1960s with the report by (Rinehart, 1960). The author stated that this inaccuracy produces "deleterious" on operational performance. Following this, it was reported that the divergence between stock record and physical stock results in "warehouse denials" (Iglehart and Morey, 1972). Their research took into consideration the frequency the depth of inventory counts and stocking policy to minimize total inventory and inspection costs.

Moreover, focusing on the significance of measuring IRI, DeHoratius and Raman (2008) showed that inventory counts may not impact record inaccuracy and additional buffer stock may not be equally necessary across all times in all stores. In fact, safety stock in the continuous- review lostsales inventory models is one of the effective inventory management policies for mitigating long run total cost.

Ritchken and Sanker (1984) used a regression- based method to adjust the size of the stock by incorporating an additional safety stock requirement in order to estimate the risk in inventory problems. Persona et al. (2007) proposed innovative cost-based analytical models for showing that one can reduce the occurrence of stock-outs by introducing a safety stock or pre-assembled modules or components.

On considering the continuous-review lost sales inventory models with a Poisson demand, Hills (2007) showed that a base- stock policy is "economically" optimal and that computing the optimal base-stock and its corresponding cost is quite simple for a backorder model. However for the lost- sales model, this policy is not optimal. Hence, the author proposed three alternative policies. Two of these involve modifying the optimal base-stock policy by imposing a delay between the placements of successive orders. The third policy is to place orders at pre-determined fixed and regular intervals. However these policies require a lot of complex calculations for lead-times under demand uncertainty. 
In addition, quantitative measures were applied and it was found out that the quality of service-level declines in a continuous review $(\mathrm{Q}, \mathrm{R})$ inventory policy when there are inventory miscounts and variations in lead- time (Kumar and Arora, 1992).

Even though most of the current research focusing on $(\mathrm{Q}, \mathrm{R})$ policy often proposes models of operational research, stimulation modeling is becoming an effective and timely tool and is capturing the cause and effect relationship in this field (Kang and Gershwin, 2004).

Urban (1995) investigated an inventory system in which the demand rate during stock out periods differs from the in-stock period demand by a given amount. The demand rate depends upon both the initial stock and the instantaneous stock. Urban formulated a profit-maximizing model and developed a closed form solution.

Datta and Pal (1990) noted that an infinite time horizon deterministic inventory system without shortage, has a level dependent demand rate up to a certain stock level and a constant demand for the rest of the cycle.

Paul et al. (1996) investigated a deterministic inventory system in which shortages are allowed and are fully back-logged. The demand is stock dependent to a certain level and then constant for the remaining periods. Hwang and Hahn (2000) constructed an inventory model for an item with an inventory-level dependent demand rate and a fixed expiry date. All units that are not sold by their expiry date are regarded as useless and therefore discarded.

The holding cost is explicitly assumed to be varying over time in only few inventory models. Shao et al. (2000) determined the optimum quality target for a manufacturing process where several grades of customers' specifications may be sold. Since rejected goods could be sold later to another customer, variable holding costs are considered in the model.

Betran and Krass (2002) analyzed the dynamic lot sizing problem with positive or negative demands and allowed disposal of excess inventory.

Goh (1994) apparently provided the only existing inventory model in which the demand is stock dependent and the holding cost is time dependent. Goh (1992) modeled the holding cost variation over time as a continuous nonlinear function, the storage time was divided into a number of distinct periods with successively increasing holding costs. As the storage time extends to the next time period, the new holding cost can be applied either retroactively (to all storage periods) or incrementally (to the new period only).

Montgomery et al. (1973) proposed a continuous review inventory system where a fraction of the unfilled demand is backordered and the remaining fraction is lost. Both the cases of deterministic and stochastic demands were considered, but the stochastic demand case was treated heuristically.

Rosenberg (1979) reformulated the above model by introducing "fictitious demand rate that simplifies the analysis of the partial backorder policy and gives an economic interpretation of the circumstances under which this policy is optimal.

Kim and Park (1985) extended the Montgomery et al.(1973) stochastic demand model to one in which the cost of a backorder is assumed to be proportional to the length of time for which the backorder exists. Assuming at most one order outstanding at any point in time and an arbitrary continuous destiny function of lead time demand, they derived the equations from which the optimal order quantity and the reorder point can be iteratively computed.

Assuming Poisson demand and an exponential lead time, Woo and Sphicas (1991) formulated a partial backorder model that allows a finite number of orders to be outstanding.

Rabinowitz et al. (1995) analyzed a (Q, r) inventory model where a fixed maximum number of backorders $b$ is allowed. During the stock out period, the first $b$ units of incoming demand are backordered and the remainder is lost. Under the assumption of Poisson demand and no more than a single order outstanding, they derive the expected annual cost function and employ an exhaustive search procedure to find the optimal values of Q,R and b. Chu et al. (2001) generalized the above model by dividing the lead time into two segments and use two backorder control limits, one for each time segment.

Posner et al. (1972) treated the case where backorder customers are willing to wait for a random period of time. The demand process is assumed to be Poisson, and the lead time and how long the customers are willing to wait are assumed to be exponentially distributed. Das (1977) used an(S-1, S) policy and assumed that customers are willing to wait for a fixed amount of time before canceling their orders. Moinzadeh (1989) also considered an $(\mathrm{S}-1, \mathrm{~S})$ inventory system with Poisson demand and a constant lead time. Smeitink (1990) proved that Moinzadeh's results hold for an arbitrary lead time and that the steady-state net inventory probabilities depend on the mean of the lead time and not on the shape of its distribution.

Chang and Dye (1999) considered a partial backordering system for deteriorating items with the backlogging rate dependent on the length of the waiting time for the next replenishment. 
Moon and Gallego (1994) introduced the distribution-free procedures in the analysis of stochastic inventory models. They solved both the continuous review and the periodic review model with a mixture of backorders and lost sales using the minimax distribution-free approach. The treatment of the periodic review model was heuristic.

Porteus (1990) reviewed stochastic periodic review models including one where a fraction of the excess demand is backordered. A myopic approximation to this model was provided by Nahmias (1979).

During the lead time there is a cut off point. Before that, if shortage occurs incoming demands will be filled by emergency orders, and after that all unfilled demands are backordered. Backorders costs are usually time dependent, that is ,they accumulate over time. DeCroix and ArreolaRisa (1998) and Cheung (1998) considered inventory systems that offer economic incentives (time -based price discount) to customers who are willing to wait longer than normal delivery times. Furthermore, Kim and Park (1985) and Park (1989) argued that the time duration of the backorder is a critical factor of the backorder costs and must be considered in an inventory system.

Given the importance of shortening the time duration of the backorder period, it is reasonable to let backorders occur close to the time when replenishment is due to arrive. Although inventory systems are typically customer driven, we do notice that there are many real systems controlled solely by the supplier. In such cases, emergency orders are often adopted instead of the lost sale policy (although they are mathematically the same) in order to maintain customer loyalty. Rabinowitz et al. (1995) considered a model for this type of inventory system. However, in their model, shortages are first backordered and the rest are filled by emergency orders. This may not be the most cost-effective because of the time - dependent cost of backorders. Furthermore, setting the time limit rather than the limit on backorders is operationally more convenient.

The assumption of no more than one outstanding order is commonly made in the existing inventory models with emergency orders or lost sales. The usage and plausibility of the assumption has been discussed in detail by Hadley and Whitin (1963), Kim and Park (1985), and Cheung (1998). In particular, Hadley and Whitin (1963) discussed the difficulty in developing the exact solutions for the lost sales case when more than one outstanding order is allowed.They argued that "If $r<Q$, then there can never be more than a single order outstanding. In the lost sales case then, it is possible to stipulate that there is only a single order outstanding if one requires that $\mathrm{r}<\mathrm{Q}$."
System Dynamics (SD) methodology aims to model real complex dynamic systems for understanding them and coming up with policies to change the problematic dynamic behavior. The real dynamic problems contain feedbacks, delays and random noise or uncertainties which make them "complex" ( Größler,2004). Feedbacks and delays are the main reasons why human- decision- making behavior results in unwanted behavior in these systems (Sterman 1989a). In most cases, the problems which SD are interested in have problematic dynamic behaviour usually caused by not optimal decisions of humans. To achieve the aim of making valid models of dynamic systems, SD tries to capture human decision making behaviour together with feedbacks and delays which are all endogenously included in the model.

In other words, SD models should be able to represent "intended rationality" of human beings (Größler, 2004). The words intended rationality or bounded rationality is used to describe the decision making behaviour of humans in these complex dynamic systems which are far from optimal. This behaviour should not be interpreted as humans acting irrationally. However, the rationality of decision maker is bounded or limited because of the complexity of many real dynamic systems (Sterman, 2000). Thus the modeler should represent the two bounded rationality of the decision maker for the model to be a valid representation of reality.

In order to model human decision- making behaviour in a certain system, one must first understand how people behave or decide in that system. Laboratory experiments were conducted where subjects play the role of the decision-maker in the model of the system to capture the behaviour of human beings. Then their decision behaviour was modeled with the help of certain heuristics and rules. Various studies that work on generic systems such as stock management problem, use laboratory experiments to come up with decision-making behaviour formulation (Sterman 1989a., b.,Dogan and Sterman 2000,Barlas and Özevin 2001). Many of these studies base their formulations on anchor and adjustment heuristic which is first proposed by Tversky and Kahnman (1982).

Clark and Scarf (1960) considered a multiechelon serial system under continuous review. Svoronos and Zipkin (1991) studied continuous review hierarchical inventory systems with exogenous stochastic replenishment lead times and one-for-one replenishment policy. By preserving the order of replenishment, the authors were able to approximate the study-state performance and to bring out the important role played by the lead time variance.

Lee and Billington (1993) used a singlenode periodic review model as a building block to 
analyze a decentralized supply chain with normally distributed demands and processing lead time.

More examples on supply chain models were proposed by Tayue et.al (1999). An extension of the standard periodic-review model is to impose a capacity limit at each stage on the maximum amounts of outputs per time unit.

$$
\text { Glasserman and Tayur }
$$

demonstrated that in a serial system with an echelon base-stock policy, the inventory and backorders are stable if the mean demand per period is less than the capacity at every node. Glasserman and Wang (1998) used a large deviations approach to obtain an asymptotic linear relationship between lead time and inventory as the fill rate approaches $100 \%$.

Zipkin (2000) provided a systematic discussion of inventory models with stochastic lead times. Based on the system structure, the models were divided into three groups: exogenous sequential systems, parallel systems and limitedcapacity systems. Exogenous sequential systems are essentially standard inventory systems with constant lead times replaced by stochastic lead times (Kaplan, 1970). In a parallel system, an infiniteserver queue is used to model the supply process. With an unlimited capacity, the order lead times are independent and identically distributed random variables.

\section{Inventory}

\section{METHODOLOGY}

The raw

materials, work-in-process goods and completely finished goods that are considered to be the portion of a business's assets that are ready or will be ready for sale. Inventory represents one of the most important assets that most businesses possess, because the turnover of inventory represents one of the primary sources of revenue generation and subsequent earnings for the company's shareholders/owners.

Possessing a high amount of inventory for long periods of time is not usually good for a business because of inventory storage, obsolescence and spoilage costs. However, possessing too little inventory is not good either, because the business runs the risk of losing out on potential sales and potential market share as well. Inventory management forecasts and strategies, such as a just-in-time inventory system, can help minimize inventory costs because goods are created or received as inventory only when needed.

\section{Types of inventory}

Several different types of inventories are conducted, depending upon the type of material involved and type of information needed.
Generally, inventory types can be grouped into four classifications. These are:

- Raw materials inventory

- Work-in-process (WIP) inventory

- Finished goods inventory

- Maintenance, repair, and operating supplies, or MRO goods

\section{Inventory Models}

Inventory analysis has two problems of importance to the organization of stock items, namely:

- Deciding when to place an order for the replenishment of the stock.

- Deciding how large an order is to be placed.

Two types of uncertainties must be considered:

a. the quantity of items that will be demanded during a given period

b. the time that will elapse between placing an order and the actual delivery of the item.

A major problem of inventory is how we can establish optimal stock levels and this is difficult because of the uncertainty of supply and demand for the commodity. Using inventory models we could formulate policies to control the system.

In some cases such as retailer, wholesaler / distributor, where items are purchased externally, if the problem of inventory exists, then there are two main questions, which generally arise and face any organization. These are how many to order and when to order. Having too much inventory reduces both purchase and /or ordering costs, but it may tie up capital, which may lead to unnecessary holding cost and possibility of deteriorating items. Whereas having too little inventory reduces the holding cost, but it can result in lost of customers, which may affect the reliability of the organization.

Answering these two questions will lead to the optimal level of inventory for any organization, which minimizes its total inventory cost.

Inventory costs, which are related to the operation of an inventory system, are caused by the actions or lack of actions that the organization is establishing.

The most common costs to an inventory system may include:

- The purchase cost of an item obtained from an external source.

- The order cost of issuing a purchase order to an outside source.

- The holding /carrying cost for keeping items in storage.

\section{Inventory Level}

This depends on the relative rates of flow in and out of the system.

Let 
$y(t)$ be rate of input flow of items at time $t$

$Y(t)$ be the cumulative flow of items into the system

$z(t)$ be the rate of flow of items out of the system time $t$

$Z(t)$ be the cumulative flow of items out of the system,

then the inventory level, $I(t)$ is the cumulative input less the cumulative output.

$$
\begin{aligned}
& I(t)=Y(t)-Z(t) \\
& I(t)=\int_{0}^{t}[y(t)-z(t)] d t \\
& I(t)=\int_{0}^{t} y(t) d t-\int_{0}^{t} z(t) d t
\end{aligned}
$$

The figure 1 below represents the inventory system when the rates vary with time. The figure might represent a raw material inventory. The flow out of inventory is relatively continuous activity where individual items are replaced into the production system for processing. To replenish the inventory, an order is placed to a supplier. After some delay time, called the lead time, the raw material is delivered in a lot of a specific amount. At the moment of delivery, the rate of input is infinite and other times it is zero. Whenever the instantaneous rates of input and output to a component is not the same, the inventory level changes. When the input rate is higher, inventory grows; when the output rate is lower, inventory declines. Usually the inventory level remains positive. This corresponds to the presence of on hand inventory. In situation where cumulative output exceeds the cumulative input, the inventory level is negative. This is what we call a backorder or shortage condition.

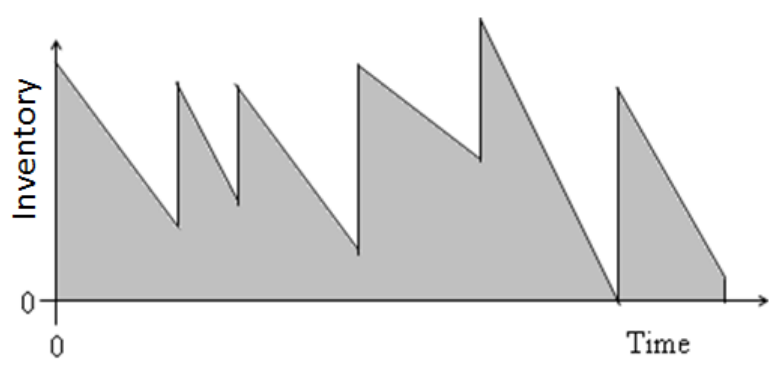

Figure 1 Inventory fluctuations as a function of time

\section{Lot-size or Economic Production Quantity (EPQ)}

The lot-size refers to the number of units in an order. The Lot-size model is designed for the production situations in which once supply begins, demand begins. During supply, demand would be reducing the inventory while supply would be adding the inventory. We assume that supply rate exceeds the demand rate during the supply run. The excess supply would cause a gradual inventory build-up during the supply period. When supply is completed, the continuing demand will cause the inventory to gradually decline until a new supply is started. The inventory pattern for this system is as shown below in figure 3.2.

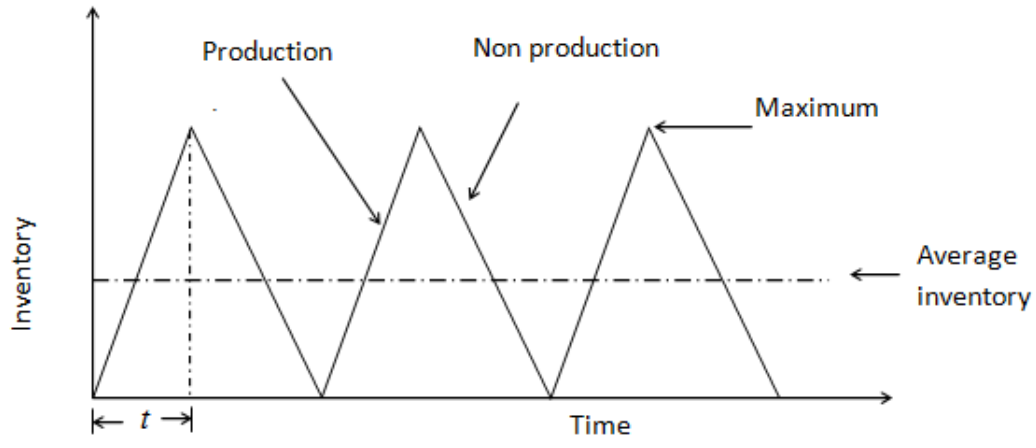

Figure 2 Inventory pattern for lot-size model

\section{Assumptions for Lot-size}

The following assumptions are considered:

- Average demand is fixed

- Demand pattern is periodic
- Average cost per order is constant

- Daily production rate is greater than daily demand rate during the production run. 


\section{Notations for lot-size}

Let:

$c_{z}=$ Ordering cost per order

$C_{h}=$ Annual holding cost per unit

$H_{c}=$ Annual Holding Cost

$n=$ Number of orders per unit time

$k=$ Annual Setup cost

$t=$ Number of days for production

$d=$ Demand rate

$D=$ Annual demand

$Q=$ Lot size

$\tau=$ Cycle time

$T=$ Cost per time

$$
=\left(1-\frac{d}{p}\right) Q
$$

$$
\begin{aligned}
\text { Average Inventory } & =\frac{1}{2} \int_{0}^{T} Q(t) d t \\
& =\frac{1}{2} \int_{0}^{T}\left[\frac{1}{T}(p-d) \frac{Q}{P}\right] d t \\
& =\frac{1}{2}\left[\frac{1}{T}(p-d) \frac{Q}{P}\right] T \\
& =\frac{1}{2}(p-d) \frac{Q}{P}
\end{aligned}
$$

$\therefore$ Average Inventory $=\frac{1}{2}\left(1-\frac{d}{p}\right) Q$

.3 .4

$\left(Q^{*}, \tau^{*}, T^{*}\right)=$ List of Optimal quantities

\section{Inventory Level Trajectory of Lot-Size Model}

The equation of the trajectory of the inventory pattern in fig. 3.2 above is of the form:

$$
Q(t)=\frac{1}{T}(p-d) t
$$

Where $p=$ daily arrival rate

$$
\begin{aligned}
& d=\text { daily demand rate } \\
& t=\text { number of days for production }
\end{aligned}
$$

Since we are assuming that $p$ will be larger than $d$, the daily inventory build-up rate during the production phase is $p-d$. If we run production for $t$ days and place $p-d$ units in the inventory each day, the inventory at the end of production will be $(p-d) t$. From the diagram above, the inventory at the end of production is also the maximum inventory. Thus

Maximum inventory $=(p-d) t$

If we are aware of producing lot-size of $Q$ units at a daily production of $p$ units, then:

$Q=p t$ and the length of production $t$ must be $t=\frac{Q}{p}$ days

Thus,

Maximum inventory $=(p-d) t$ $=(p-d)\left(\frac{Q}{p}\right)$

\section{Development of the Optimal Order Quantity for} Lot-Size Model

We develop below the Lot-size model through the construction of the total inventory cost model.

Let the annual holding cost per unit be $C_{h}$, the equation for annual holding cost is

Annual Holding Cost $=($ Average inventory $)($ Annual cost per unit $)$

$$
H_{c}=\frac{1}{2}\left(1-\frac{d}{p}\right) Q C_{h}
$$

If $D$ is the annual demand for the product and $k$ is the setup cost per production then the annual setup cost is

Annual Setup or Ordering Cost $=($ Number production per

$=\frac{D}{Q} k$

Thus, the total annual cost $T_{c}$ model is

$T_{c}=\frac{1}{2}\left(1-\frac{d}{p}\right) Q C_{h}+\frac{D}{Q} k$

Suppose that facility operates 250 days per year .Then we write daily demand $d$ in terms of annual demand $D$ as follows:

$d=\frac{D}{250}$

Now let $P$ denotes the annual production if the product were produced every day Then,

$P=250 p \quad$ and $\quad p=\frac{P}{250}$

Thus, 


$$
\frac{d}{p}=\frac{\left(\frac{D}{250}\right)}{\left(\frac{P}{250}\right)}=\frac{D}{P}
$$

Therefore the total annual cost model can also be written as

$$
T_{c}=\frac{1}{2}\left(1-\frac{D}{P}\right) Q C_{h}+\frac{D}{Q} k
$$

Setting to zero the derivative of $T_{c}$ with respect to $Q$, we obtain

$$
\begin{aligned}
& \frac{d T_{c}}{d Q}=0 \\
\Rightarrow & \frac{1}{2}\left(1-\frac{D}{P}\right) C_{h} Q^{2}=2 D k \\
\Rightarrow & Q^{2}=\frac{2 D k}{\left(1-\frac{D}{P}\right) C_{h}}
\end{aligned}
$$

Solving for order quantity optimality policy we have

$$
Q^{*}=\sqrt{\frac{2 D k}{\left(1-\frac{D}{P}\right) C_{h}}}
$$

and

$$
\tau^{*}=\frac{Q^{*}}{d}
$$

Substitute optimal lot-size, $Q^{*}$, into the total cost expression, $T_{c}$,

\section{Periodic Review Inventory System}

An alternative to the continuous review system is the periodic review inventory system. With a periodic review, the inventory may be checked and orders placed on a weekly, bi-weekly, tri-weekly, monthly or some other periodic basis.

\section{Replenishment Level (M)}

It is inventory level at which the order quantity should be demanded at the review period. If the normal probability distribution is used then:

$M=d+z s$ Where

$\mathrm{d}=$ mean demand

$\mathrm{z}=$ number of standard deviations necessary to obtain the acceptable stockout probability

$\mathrm{s}=$ standard deviation of the distribution

\section{How-Much-To-Order Decision}

The how-much-to-order decision at any review period is determined using the model

$$
T_{c}^{*}=\frac{1}{2}\left(1-\frac{D}{P}\right) Q^{*} C_{h}+\frac{D}{Q^{*}} k
$$

Note: As the production rate $p$ approaches infinity, $\frac{D}{p}$ approaches zero. That is $\left(1-\frac{D}{p}\right)$ representing probability of no shortage.

At optimum, the total holding cost is equal to total ordering or set-up cost.

\section{Stock out and service level}

Stockout: Stockout occurs when there is insufficient stock to satisfy customers demand.

Service level $=1-p$ (stockout)

Taylor (2006), Anderson (2004)

\section{Effective Inventory Cost Decision for Lot-Size} Model

Holding cost, normal inventory $=\frac{1}{2}\left(1-\frac{D}{P}\right) Q C_{h}$ Minimum holding cost $=\frac{1}{2}\left(1-\frac{D}{P}\right) Q^{*} C_{h}$

i.e $\frac{1}{2}\left(1-\frac{D}{P}\right) Q^{*} C_{h}<\frac{1}{2}\left(1-\frac{D}{P}\right) Q C_{h}$

3) $\quad$ Ordering $\operatorname{Cost}=\left(\frac{D}{Q}\right) k$

4) Minimum Ordering Cost $=\left(\frac{D}{Q^{*}}\right) k$

i.e $\left(\frac{D}{Q^{*}}\right) k<\left(\frac{D}{Q}\right) k$

Let:

$q=M-X$ Where

q Represents the order quantity at review period $\mathrm{M}=$ replenishment level

$\mathrm{X}=$ the inventory on hand at review period which varies since demand is probabilistic.

Taylor (2006), Anderson (2004)

\section{Retroactive Holding Cost and Incremental Increase Cost Models}

There is no question that uncertainty plays in most inventory management situations. The retail merchant wants enough supply to satisfy costumer demands but ordering too much increase holding costs and the risk of losses through obsolescence or spoilage. An order too small increases the risk of lost sales and unsatisfied customers. These situations are common, and answers one gets from deterministic analysis very often are not satisfactory when uncertainty is present. 
The model that will be developed for the inventory system is based on allowing unit holding cost values to vary across different storage periods. Variable unit holding costs are considered in the model in determining the optimal policy. The holding cost per unit is assumed to increase only when the storage time exceeds specific discrete values. That is the holding cost per unit time is an increase step function of the storage time. Two type of holding cost step functions will be considered:

- Retroactive increase; the unit holding cost rate of the last storage period is applied to all storage period.

- Incremental increase; Higher storage cost rates is applied to storage in later periods.

\section{Notations for Retroactive Holding Cost and} Incremental Increase Cost

The following notations are adopted from Goh (1992) for the model under consideration for Agricare inventory system.

$q(t)$ : the on - hand inventory at time $\mathrm{t}$

$D$ : constant(base)demand rate

$n$ : number of distinct time periods with different inyentfory deseld decrease, we can describe inventory : numel $q$ by the following differential equation:

$t:$ time from the start of the cycle at $\mathrm{t}=0$

$t_{i}:$ end time of period $i$, where $i=1,2, \ldots, n, t_{0}=0$

$\frac{d q(t)}{d t}=-D[q(t)]^{\beta}$

$$
D>0,0 \leq t \leq T, 0<\beta<1
$$

\section{$k$ : ordering cost per order}

$h_{i}$ : holding cost of the item in period $i$

$h(t)$ : holding cost of the item at time $t, h(t)=h_{i}$ if $\underset{q}{\text { evaluated by solving equation (3): }}$

\section{$T$ : cycletime \\ Assumptions and Limitations for Retroactive Holding Cost and Incremental Holding Increase Cost}

Integrating both sides:

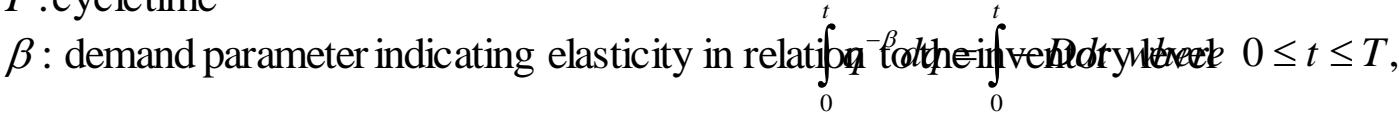

The following assumptions and limitations are considered:

- The demand rate $\mathrm{R}$ is an increasing step function of the inventory level $\mathrm{q}$.

- The holding cost is varying as an increasing step function of time in storage.

- Replenishments are instantaneous.

- Shortages are not allowed.

- A single item is considered.

- The demand rate $\mathrm{R}$ dependence on the inventory level $\mathrm{q}$ is expressed as $R(q)=D q^{\beta}, D>0,0<\beta<1, q \geq 0$
$\left.\Rightarrow \frac{q^{1-\beta}}{(1-\beta)}\right|_{0} ^{t}=-D t$,

$\Rightarrow q^{1-\beta}(t)-q^{1-\beta}(0)=-D(1-\beta) t$

$\Rightarrow q^{1-\beta}(t)=-D(1-\beta) t+q^{1-\beta}(0)$

However,

$q^{1-\beta}(0)=Q^{1-\beta}$,

Thus,

$$
\begin{gathered}
q^{1-\beta}(t)=-D(1-\beta) t+Q^{1-\beta}, \\
q(t)=\left[-D(1-\beta) t+Q^{1-\beta}\right]^{\frac{1}{(1-\beta)}}
\end{gathered}
$$

The period $T$ can be evaluated by substituting the inventory function $q(t)$ at $T$.

That is: 


$$
\begin{aligned}
& q(T)=0 \\
& \Rightarrow q(T)=\left[-D(1-\beta) T+Q^{1-\beta}\right] \frac{1}{(1-\beta)}=0 \\
& \Rightarrow-D(1-\beta) T-q^{1-\beta}(T)=-Q^{1-\beta} \\
& T\left(-D(1-\beta)-q^{1-\beta}\right)=-Q^{1-\beta}
\end{aligned}
$$

Hence,

$$
T=\frac{Q^{1-\beta}}{D(1-\beta)+q^{1+\beta}}
$$$$
\text { -.....3.16a }
$$

Or

$$
Q=\left[D(1-\beta) T+q^{1-\beta}\right]^{\frac{1}{(1-\beta)}}
$$

\section{Retroactive Holding Cost Increase}

The holding cost is assumed to be an increasing step function of storage time, that is $h_{1}<h_{2}<h_{3} \ldots<h_{n}$. Here, a uniform holding cost that depends on the length of storage is used. Specifically, the holding cost of the last storage period applies retroactively to all previous storage periods. Thus, if the cycle ends at in period, $e$, with $\left(t_{e-1} \leq T \leq t_{e}\right)$ then the holding cost rate $h_{e}$ is applied to all periods $1,2, \ldots, e$. In this case; the TIC per unit time can be expressed as

$T I C=\frac{k}{T}+\frac{h_{i}}{T} \int_{0}^{T} q(t) d t$,

where $t_{i-1} \leq T \leq t_{i}$

Substituting the value of $q(t)$ from (3.1.5)

$$
\begin{aligned}
\text { TIC } & =\frac{k}{T}+\frac{h_{i}}{T} \int_{0}^{t}\left[-D(1-\beta) t+Q^{1-\beta}\right]^{\frac{1}{(1-\beta)}} d t T, \\
& =\frac{k}{T}-\frac{h_{i}}{D(2-\beta) T}\left[-\left.D(1-\beta)\right|_{0} ^{T}+Q^{1-\beta}\right]^{\frac{(2-\beta)}{(1-\beta)}}
\end{aligned}
$$

Thus,

$T I C=\frac{k}{T}+\frac{h_{i}}{D(2-\beta) T} \times\left[\left[Q^{1-\beta}\right]^{\left(\frac{2-\beta)}{(1-\beta)}\right.}-\left[-D(1-\beta) T+Q^{1-\beta}\right]^{(2-\beta)}\right]$

Substituting the value of $T$ from (4.2.4)
$T I C=\frac{k D(1-\beta)}{Q^{1-\beta}}+\frac{h_{i}(1-\beta) Q}{(2-\beta)}$,

where $t_{i-1} \leq T \leq t_{i}$

Setting the derivative of $T I C$ with respect to $Q$ equal to zero and solving for $Q$, we obtain:

$Q *=\left[\frac{k D(1-\beta)(2-\beta)}{h_{i}}\right]^{\frac{1}{(2-\beta)}}, t_{i-1} \leq T \leq t_{i}$

\section{Solution Algorithm}

The optimum solution can be determined by using the following solution algorithm steps, Alfares (2007):

1. Beginning with the lowest holding $\operatorname{cost} h_{1}$, using

$Q *=\left[\frac{k D(1-\beta)(2-\beta)}{h_{i}}\right]^{\frac{1}{(2-\beta)}}, t_{i-1} \leq T \leq t_{i}$

to determine $Q$ and $T=\frac{Q^{1-\beta}}{D(1-\beta)}$ to determine $T$ for each $h_{i}$ until $Q$ is realizable $i e\left(t_{i-1} \leq T \leq t_{i}\right)$. Call these values $T_{R}$ and $Q_{R}$.

2. Use $Q=[D(1-\beta) T]^{\frac{1}{(1-\beta)}}$ to calculate all break-point values of $Q$, $Q_{i}=Q\left(t_{i}\right), t_{1} \leq T<T_{R}$; each $Q_{i}$ is obtained by substituting $t_{i}$ into $Q=[D(1-\beta) T] \frac{1}{(1-\beta)}$.

3. Use $T I C=\frac{k D(1-\beta)}{Q^{1-\beta}}+\frac{h_{i}(1-\beta) Q}{(2-\beta)}$, $t_{i-1} \leq T \leq t_{i}$ to calculate the TIC for $Q_{R}$ and each $Q_{i}$

4. Choose the value of $Q$ that gives the lowest TIC.

\section{Incremental Holding Cost Increase}

The holding cost is now assumed to be an incremental step function of the storage time. According to this function, higher storage cost rate apply to storage in later periods. Thus, if the cycle ends in period, $e$, with $\left(t_{e-1} \leq T \leq t_{e}\right)$, then holding cost rate $h_{1}$ is applied to period 1 , rate $h_{2}$ is applied to period 2, and so on; thus rate $h_{e}$ is applied only to period $e$ from time $t_{e-1}$ up to time T. For 
this we reset the value of $t_{e}$ as $\left(t_{e}=\mathrm{T}\right)$, and then express the TIC per unit time as:

$$
\begin{aligned}
& \mathrm{TIC}=\frac{k}{T}+\frac{h_{1}}{T} \int_{0}^{t_{1}} q(t) d t+\frac{h_{2}}{T} \int_{t_{1}}^{t_{2}} q(t) d t+\ldots+\frac{h_{e}}{T} \int_{t_{e-1}}^{t_{e}=T} q(t) d t \\
& 3.20
\end{aligned}
$$

Substituting the value of $q(t)$ from eqn. (4.2.3), we obtain:

Substituting the value of $\mathrm{T}$ from eqn. (4.2.4), and rearranging and simplifying terms gives:

$\mathrm{TIC}=\frac{k D(1-\beta)}{Q^{1-\beta}}+\frac{h_{i}(1-\beta) Q}{(2-\beta)}+\sum_{i=1}^{e-1} \frac{\left(h_{i+1}-h_{i}\right)(1-\beta)}{Q^{1-\beta}(2-\beta)} \times\left[Q^{1-\beta}-D(1-\beta) t_{i}\right]^{\left(\frac{2-\beta)}{(1-\beta)}\right.}$ ...3.21

To find the optimal order size $Q^{*}$, we set the derivative TIC with respect to $Q$ equal to zero.

After simplification, we obtain:

$$
\begin{aligned}
& -\frac{k D(1-\beta)}{Q^{1-\beta}}+\frac{h_{1} Q}{(2-\beta)}+\sum_{i=1}^{c-1}\left(h_{i+1}-h_{i}\right)\left[Q^{1-\beta}-D(1-\beta) t_{i}\right]^{\frac{1}{(1-\beta)}}-\sum_{i=1}^{e-1} \frac{\left(h_{i+1}-h_{i}\right)(1-\beta)}{Q^{1-\beta}(2-\beta)} \\
& \times\left[Q^{1-\beta}-D(1-\beta) t_{t_{i}}\right]^{\left(\frac{2-\beta)}{1-\beta)}\right.}=0 \\
& \ldots \ldots \ldots . .3 .22
\end{aligned}
$$

If the entire inventory cycle happens to fall into the first period $\left(0 \leq \mathrm{T} \leq t_{1}\right)$, then $e=1$ and the summations over $i$ in eqn. 3.22 are empty. In that case the optimum solution is simply obtained by substituting $h_{1}$ into eqn. 3.19 to calculate $Q^{*}$, and then substituting $Q^{*}$ into eqn. 3.15 to calculate T. obviously, a simple closed form solution for $Q^{*}$ and $T^{*}$ can be determined only if $T \leq t_{1}$.

In general, the optimum solution must be determined by the following solution algorithm steps, Alfares (2007).

\section{Solution Algorithm}

1. Substitute $h_{1}$ into

$Q *=\left[\frac{k D(1-\beta)(2-\beta)}{h_{i}}\right]^{\frac{1}{(2-\beta)}}$,

$Q^{*}=t_{i-1} \leq T \leq t_{i}$ to determine $Q_{\max }$, and then substitute $Q_{\max }$ into $T=\frac{Q^{1-\beta}}{D(1-\beta)}$ to determine $T_{\max }$. If $\mathrm{T}_{\max } \leq \mathrm{t}_{1}$, stop; the solution $\left(Q_{\max } T_{\max }\right)$ is optimal.
2. Substitute
$h_{n}$ into

to determine $Q_{\min }$, and Substitute $Q_{\min }$ into $T=\frac{Q^{1-\beta}}{D(1-\beta)}$ to determine $T_{\min }$

3. Depending on the values of $T_{\min }$ and $T_{\max }$, determine the possible periods that $\mathrm{T}$ may fall into (i.e., all feasible values of $e$ ).

4. For each feasible value of $e$, solve

$$
\begin{aligned}
& -\frac{k D(1-\beta)}{Q^{1-\beta}}+\frac{h_{1} Q}{(2-\beta)}+\sum_{i=1}^{e-1}\left(h_{i+1}-h_{i}\right)\left[Q^{1-\beta}-D(1-\beta) t_{i}\right]^{\frac{1}{1-\beta)}}-\sum_{i=1}^{c-1} \frac{\left(h_{i+1}-h_{i}\right)(1-\beta)}{Q^{1-\beta}(2-\beta)} \\
& \times\left[Q^{1-\beta}-D(1-\beta) t_{i}\right]^{(1-\beta)}=0
\end{aligned}
$$

numerically to determine the optimum value of $Q$. If $Q$ corresponds to the correct period, it is considered realizable.

5. Using $\mathrm{TIC}=\frac{k D(1-\beta)}{Q^{1-\beta}}+\frac{h_{i}(1-\beta) Q}{(2-\beta)}+\sum_{i=1}^{e-1} \frac{\left(h_{i+1}-h_{i}\right)(1-\beta)}{Q^{1-\beta}(2-\beta)} \times\left[Q^{1-\beta}-D(1-\beta) t_{i}\right]^{\left(\frac{2-\beta)}{1-\beta)}\right.}$ , calculate TIC for $Q_{R}$ and each $Q_{i}=Q\left(t_{i}\right)$

6. Choose the value of $Q$ that gives the lowest TIC

\section{DATA COLLECTION, ANALYSIS AND RESULTS}

\section{Data Collection and Description}

The data for this project was obtained from Inventory Department of Mantrac Ghana Limited on stock, demand and supply of Hoses covering a period of six years on monthly basis.

Stock: The goods or merchandise kept on the premises of a business or warehouse and available for sale or distribution.

Demand: An economic principle that describes a consumer's desire and willingness to pay a price for a specific good or service. Holding all other factors constant, the price of a good or service increases as its demand increases and vice versa.

Supply: A fundamental economic concept that describes the total amount of a specific good or service that is available to consumers. Supply can relate to the amount available at a specific price or the amount available across a range of prices if displayed on a graph. This relates closely to the demand for a good or service at a specific price; all else being equal, the supply provided by producers will rise if the price rises because all firms look to maximize profits.

The data comprises the following:

- $\quad$ Monthly data on stock, demand and supply of Hoses from January 2005 to December 2010.

$$
Q^{*}=\left[\frac{k D(1-\beta)(2-\beta)}{h_{i}}\right]^{\frac{1}{(2-\beta)}}, Q^{*}=t_{i-1} \leq T \leq t_{i}
$$

Table 1: Stock, demand and supply data of Hoses for January, 2005 to December, 2010.

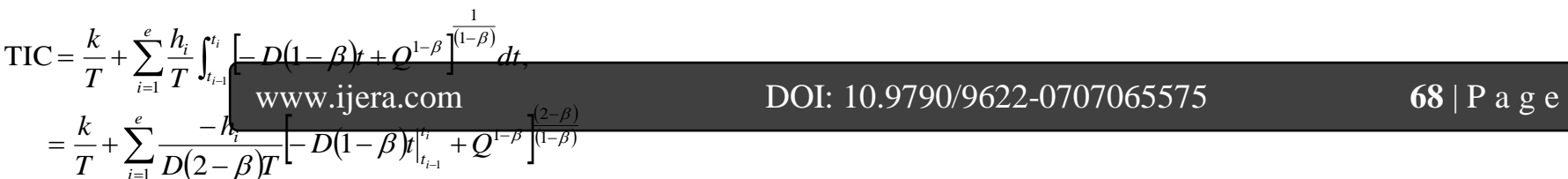



ISSN : 2248-9622, Vol. 7, Issue 7, ( Part -6) July 2017, pp.55-75

\begin{tabular}{|c|c|c|c|c|c|c|c|c|c|c|}
\hline YEAR & \multicolumn{3}{|c|}{2005} & \multicolumn{3}{|c|}{2006} & $\ldots$ & \multicolumn{2}{|c|}{2010} & \\
\hline MONTH & STOCK & DEMAND & SUPPLY & STOCK & DEMAND & SUPPLY & $\ldots$ & STOCK & DEMAND & SUPPLY \\
\hline JAN & 2400 & 1804 & 1804 & 3500 & 1405 & 1405 & $\ldots$ & 3200 & 1850 & 1850 \\
\hline FEB & 2060 & 2045 & 2045 & 2600 & 1975 & 1975 & $\ldots$ & 3400 & 2135 & 2135 \\
\hline MARCH & 2500 & 1750 & 1750 & 4000 & 4128 & 4000 & $\ldots$ & 3500 & 3590 & 3500 \\
\hline APRIL & 1500 & 251 & 251 & 4500 & 2145 & 2145 & $\ldots$ & 4000 & 3250 & 3250 \\
\hline MAY & 1400 & 468 & 468 & 4800 & 2694 & 2694 & $\ldots$ & 3840 & 2850 & 2850 \\
\hline JUNE & 900 & 390 & 390 & 3000 & 1945 & 1945 & $\ldots$ & 3000 & 2000 & 2000 \\
\hline JULY & 1000 & 1005 & 1000 & 4100 & 3056 & 3056 & $\ldots$ & 3010 & 3045 & 3010 \\
\hline AUG & 2000 & 1065 & 1065 & 3500 & 2043 & 2043 & $\ldots$ & 4500 & 2800 & 2800 \\
\hline SEPT & 935 & 50 & 50 & 1000 & 632 & 632 & $\ldots$ & 3000 & 900 & 900 \\
\hline OCT & 3500 & 3567 & 3500 & 2000 & 1024 & 1024 & $\ldots$ & 2100 & 610 & 610 \\
\hline NOV & 4000 & 1157 & 1157 & 1200 & 380 & 380 & $\ldots$ & 1490 & 780 & 780 \\
\hline DEC & 3000 & 4309 & 3000 & 1500 & 1902 & 1500 & $\ldots$ & 1000 & 1200 & 1000 \\
\hline AVERAGE & 2099.58 & 1488.42 & & 2975 & 1944.08 & & $\ldots$ & 3003.33 & 2084.17 & \\
\hline
\end{tabular}

Average annual demand $=\quad 23182.32$ units Average annual stock $\quad=\quad 32207.88$ units The stock, demand and supply data for January, 2007 to December 2010 is displayed in appendix A. The average stock and demand for each year was displayed in the last rows of the table. The average monthly stock for the six years period was $\mathbf{2 6 8 4}$ and that of demand was $\mathbf{1 9 3 2}$.

- Inventory holding cost per unit per year and fixed ordering cost per inventory cycle as at the year 2010 are displayed in the table below.

Table 2: Data on cost components

\begin{tabular}{|l|l|}
\hline COST & AMOUNT $(\mathbf{G H} \boldsymbol{c})$ \\
\hline Ordering cost per order $(\mathrm{k})$ & 58.00 \\
\hline Holding cost period one $\left(\mathrm{h}_{1}\right)$ & 2.90 \\
\hline Holding cost period two $\left(\mathrm{h}_{2}\right)$ & 3.90 \\
\hline Holding cost period three $\left(\mathrm{h}_{3}\right)$ & 4.90 \\
\hline Holding cost period four $\left(\mathrm{h}_{4}\right)$ & 5.90 \\
\hline
\end{tabular}

The costs are in Ghana cedis.

\section{Stock, Demand and Supply data compared}

Figure 3, below displays the trajectory of stock, demand and supply data from January 2005 to December 2010. A cursory look at the pattern of the graph shows that during most of the periods, the stock was more than the demand and supply. However, a careful observation of the pattern of the graph shows the incidence of periodicity with high and low points. During some months, the demand was more than the stock and supply and this will result into backorders and lost sales which is one of the problems of the company.

The high demands during this period are due to some factors such as the low humidity which cause the hose to wear off very early because those periods are in the harmattan. Also because the grounds are very hard during those periods, the hydraulic systems of the excavators which make use of the hose do wear off quickly because of the difficulties the excavators experienced when excavating.

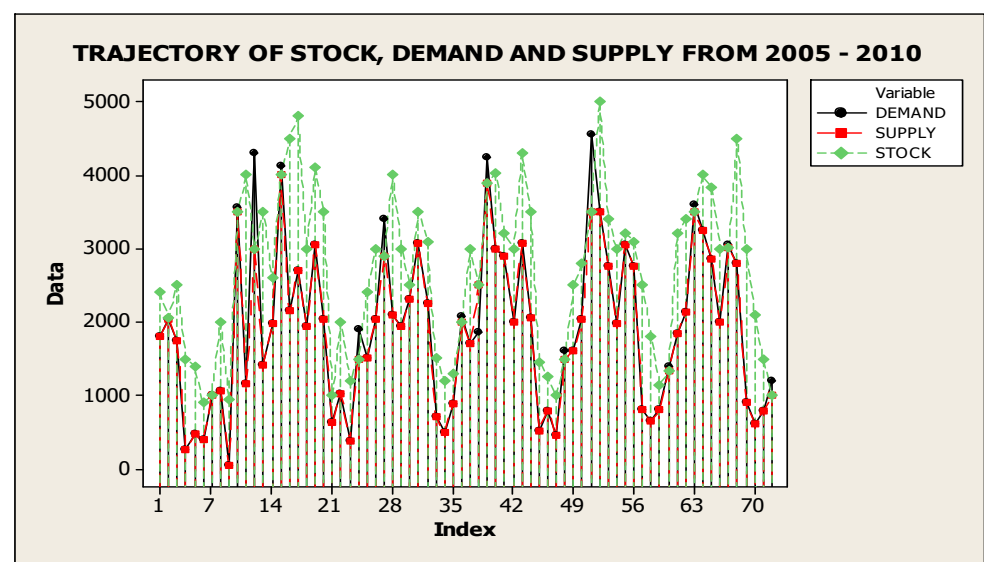

Figure 3 Trajectory of Stock, demand and supply from 2005 - 2010

\section{Computational procedures}

The following values were used in the computations. 
Average annual demand (D)

$$
\begin{gathered}
=\frac{\text { Total average demand }}{6 \text { years }} \times 12 \text { months } \\
=\quad \frac{11591.17}{6} \times 12 \\
=\quad 1931.86 \times 12
\end{gathered}
$$

units

Ordering cost per order $(\mathrm{k})$

Inventory holding cost per unit year $(\mathrm{h})$

$=\mathrm{GH} \phi 58.00$

$=\quad \mathrm{GH} \phi 2.90$

According to H.K Alfares( 2007), fraction of demand backordered during stock out period $(\beta) \quad=\quad 0.1$

Holding Cost for period one $\mathrm{h}_{1}=\mathrm{GH} \notin 2.90 /$ unit year $0<\mathrm{T} \leq 0.2, \mathrm{t}_{1}=0.2$ year

Holding Cost for period two $\mathrm{h}_{2}=\mathrm{GH} \notin 3.90 /$ unit year $0.2<\mathrm{T} \leq 0.4, \mathrm{t}_{2}=0.4$ year

Holding Cost for period three $\mathrm{h}_{3}=\mathrm{GH} \phi 4.90 /$ unit year $0.4<\mathrm{T} \leq 0.6, \mathrm{t}_{3}=0.6$ year

Holding Cost for period four $\mathrm{h}_{4}=\mathrm{GH} \phi 5.90 /$ unit year $0.6<\mathrm{T} \leq 0.8, \mathrm{t}_{4}=0.8$ year etc.

The following computations were made using Retroactive Holding Cost solution algorithm.

Alfares (2007):

\section{- Solution algorithm}

step 1:

Using $Q *=\left[\frac{k D(1-\beta)(2-\beta)}{h_{i}}\right]^{\frac{1}{(2-\beta)}}$, to compute $Q$, and $T=\frac{Q^{1-\beta}}{D(1-\beta)+q^{1+\beta}}$ to determine $\mathrm{T}$ for each $h_{i}$ until $\mathrm{Q}$ is realizable $\left(\right.$ i.e. $\left.t_{i-1} \leq T \leq t_{i}\right)$. Call these values $\mathrm{Q}_{\mathrm{R}}$ and $\mathrm{T}_{\mathrm{R}}$.

Begin with $h_{1}=\mathrm{GH} \notin 2.90$

$$
\Rightarrow \quad \mathrm{Q} *=\left[\frac{58(2683.985)(1-0.1)(2-0.1)}{2.90}\right]^{\frac{1}{(2-0.1)}}=409.2637 \text { units }
$$

The corresponding cycle time, $\mathrm{T}=\frac{(409.2637)^{(1-0.1)}}{2683.985(1-0.1)}=0.0928$ ( realizable)

since $0<\mathrm{T} \leq 0.2$.

When $h_{2}=\mathrm{GH} \notin 3.90$

$\Rightarrow \quad \mathrm{Q} *=\left[\frac{58(2683.985)(1-0.1)(2-0.1)}{3.90}\right]^{\frac{1}{(2-0.1)}}=350.1741$ units

The corresponding cycle time, $\mathrm{T}=\frac{(350.1741)^{(1-0.1)}}{2683.985(1-0.1)}=0.0807$ (not realizable)

since $0.2<\mathrm{T} \leq 0.4$.

When $h_{3}=\mathrm{GH} \notin 4.90$

$\Rightarrow \quad \mathrm{Q} *=\left[\frac{58(2683.985)(1-0.1)(2-0.1)}{4.90}\right]^{\frac{1}{(2-0.1)}}=310.5343$ units

The corresponding cycle time, $\mathrm{T}=\frac{(310.5343)^{(1-0.1)}}{2683.985(1-0.1)}=0.0724$ (not realizable)

since $0.4<\mathrm{T} \leq 0.6$

When $\mathrm{h} 4=\mathrm{GH} \varnothing 5.90$

$\Rightarrow \quad \mathrm{Q} *=\left[\frac{58(2683.985)(1-0.1)(2-0.1)}{5.90}\right]^{\frac{1}{(2-0.1)}}=281.6171$ units

The corresponding cycle time, $\mathrm{T}=\frac{(281.6171)^{(1-0.1)}}{2683.985(1-0.1)}=0.0663$ (not realizable)

Since $0.6<\mathrm{T} \leq 0.8$.

This is repeated until realizable $\mathrm{Q}_{\mathrm{R}}$ and $\mathrm{T}_{\mathrm{R}}$ are obtained for $\mathrm{h}_{1}<\mathrm{h}_{2}<\mathrm{h}_{3}<\ldots \mathrm{h}_{\mathrm{n}}$. From above, and $\mathrm{T}_{\mathrm{R}}=0.0928$

The table below displays the results for Solution Algorithm step1:

Table3: Results of Solution Algorithm step1 

ISSN : 2248-9622, Vol. 7, Issue 7, ( Part -6) July 2017, pp.55-75

\begin{tabular}{|l|l|l|l|l|}
\hline & $\mathbf{Q}$ & $\mathbf{T}$ & $\left(\right.$ i.e. $\left.t_{i-1} \leq T \leq t_{i}\right)$ & Remark(s) \\
\hline $\mathrm{h}_{\mathbf{i}}=\mathrm{GH} \phi 2.90$ & 409.2637 & 0.0928 & $0<\mathrm{T} \leq 0.2$ & Realizable \\
\hline $\mathrm{h}_{2}=\mathrm{GH} \phi 3.90$ & 350.1741 & 0.0807 & $0.2<\mathrm{T} \leq 0.4$ & Not realizable \\
\hline $\mathrm{h}_{3}=\mathrm{GH} \phi 4.90$ & 310.5343 & 0.0724 & $0.4<\mathrm{T} \leq 0.6$ & Not realizable \\
\hline $\mathrm{h}_{4}=\mathrm{GH} \phi 5.90$ & 281.6171 & 0.0663 & $0.6<\mathrm{T} \leq 0.8$. & Not realizable \\
\hline
\end{tabular}

\section{Step 2:}

Calculating all break points of $Q, Q_{i}=Q\left(t_{i}\right), t_{1} \leq T<T_{R}$; each $Q_{i}$ is obtained by substituting $t_{i}$ into $Q=[D(1-\beta) T]^{\frac{1}{(1-\beta)}}$

We have:

When $\mathrm{t}_{1}=0.2$

$\Rightarrow \mathrm{Q}_{1}=[2683.985(1-0.1) 0.2]^{\frac{1}{(1-0.1)}}=960.0208$ units

When $\mathrm{t}_{2}=0.4$

$\Rightarrow \mathrm{Q}_{2}=[2683.985(1-0.1) 0.4]^{\frac{1}{(1-0.1)}}=2073.8$ units

When $\mathrm{t}_{3}=0.6$

$\Rightarrow \mathrm{Q}_{3}=[2683.985(1-0.1) 0.6]^{\frac{1}{(1-0.1)}}=3254.0$ units

When $\mathrm{t}_{4}=0.8$

$\Rightarrow \mathrm{Q}_{4}=[2683.985(1-0.1) 0.8]^{\frac{1}{(1-0.1)}}=4479.6$ units

The table below displays the result for Solution Algorithm step2:

Table 4: Results of Solution Algorithm step2

\begin{tabular}{|l|l|}
\hline $\mathbf{T}$ & $\mathbf{Q}_{\mathbf{i}}$ \\
\hline $\mathrm{t}_{1}=0.2$ & $\mathrm{Q}_{1}=960.0208$ \\
\hline $\mathrm{t}_{2}=0.4$ & $\mathrm{Q}_{2}=2073.8$ \\
\hline $\mathrm{t}_{3}=0.6$ & $\mathrm{Q}_{3}=3254.0$ \\
\hline $\mathrm{t}_{4}=0.8$ & $\mathrm{Q}_{4}=4479.6$ \\
\hline
\end{tabular}

From the table the minimum $\mathrm{Q}_{\mathrm{i}}$ is $\mathrm{Q}_{1}=960.0208$.

Step 3:

Using $T I C=\frac{k D(1-\beta)}{Q^{1-\beta}}+\frac{h_{i}(1-\beta) Q}{(2-\beta)}, \quad t_{i-1} \leq T \leq t_{i}$ to calculate the TIC using $\mathrm{Q}_{\mathrm{R}}=409.2637$ units and each $\mathrm{Q}_{1}$

we have:

for $\mathrm{Q}_{\mathrm{R}}=409.2637$ units,

$\Rightarrow$ TIC $(409.2637)=\frac{58(2683.985)(1-0.1)}{(409.2637)^{(1-0.1)}}+\frac{2.90(1-0.1)(409.2637)}{(2-0.1)}=1186.9$

For $\mathrm{Q}_{1}=960.0208$ units,

$\Rightarrow$ TIC $(960.0208)=\frac{58(2683.985)(1-0.1)}{(960.0208)^{(1-0.1)}}+\frac{2.90(1-0.1)(960.0208)}{(2-0.1)}=1608.8$

For $\mathrm{Q}_{2}=2073.8$ units,

$\Rightarrow$ TIC $(2073.8)=\frac{58(2683.985)(1-0.1)}{(2073.8)^{(1-0.1)}}+\frac{3.90(1-0.1)(2073.8)}{(2-0.1)}=3976.1$

For $\mathrm{Q}_{3}=3254$ units,

$\Rightarrow$ TIC $(3254)=\frac{58(2683.985)(1-0.1)}{(3254)^{(1-0.1)}}+\frac{4.90(1-0.1)(3254)}{(2-0.1)}=7649.4$

For $\mathrm{Q}_{4}=4479.6$ units,

$\Rightarrow$ TIC $(4479.6)=\frac{58(2683.985)(1-0.1)}{(4479.6)^{(1-0.1)}}+\frac{5.90(1-0.1)(4479.6)}{(2-0.1)}=1259.2$

The table below displays the $\mathrm{Q}^{*}$ and $\mathrm{TIC}^{*}$ for solution algorithm step3:

Table 5: Results of TIC using $Q_{R}$ and $Q_{i}$ 


\begin{tabular}{|l|c|}
\hline $\mathbf{Q}^{*}$ & TIC $^{*}$ \\
\hline $\mathrm{Q}_{\mathrm{R}}{ }^{*}=409.0208$ & 1186.9 \\
\hline $\mathrm{Q}_{1}{ }^{*}=960.0208$ & 1608.8 \\
\hline $\mathrm{Q}_{2}{ }^{*}=2073.8$ & 3976.1 \\
\hline $\mathrm{Q}_{3}{ }^{*}=3254$ & 7649.4 \\
\hline $\mathrm{Q}_{4}{ }^{*}=4479.6$ & 1259.2 \\
\hline
\end{tabular}

\section{Step 4:}

Choose the value of $\mathrm{Q}$ that gives the lowest TIC.

From table 5, the value of $\mathrm{Q}$ that gives the lowest Total Inventory Holding Costs (TIC) is 409.2637 and corresponding minimum Total Inventory Cost $\mathrm{TIC}^{*}=\mathrm{GH} \not 1186.9$ the cycle period realizable for this order quantity $\mathrm{Q}^{*}$ and $\mathrm{TIC}^{*}$ is 0.2 year.

\section{SUMMARY, CONCLUSIONS AND RECOMMENDATIONS \\ Summary}

From the Solution Algorithm step 1, a cycle time of 0.0928 gives a realizable value. This gives an optimum quantity of $\mathbf{4 0 9 . 0 2 0 8}$ units and Total Inventory Cost of GH $\mathbf{1 1 8 6 . 9 0}$.

Low quantity costs with corresponding higher cycle times results in Low Total Inventory Cost as could be observed across the table 3 . Also, the higher the optimum cost, the higher the Total Inventory Cost. The Total Inventory Cost also depends on the cycle time. However, cycle times of $0.0807,0.0724$ and 0.0663 gave unrealizable values as could be seen in the table below.

Table 6: Quantity, Cycle time and Total Inventory Cost

\begin{tabular}{|l|l|l|l|}
\hline Q* & Cycle time, T & TIC $(\mathrm{GH} \phi)$ & \\
\hline 409.0208 & 0.0928 & 1186.9 & Realizable \\
\hline 960.0208 & 0.0807 & 1608.8 & Not realizable \\
\hline 2073.8 & 0.0724 & 3976.1 & Not realizable \\
\hline 3254 & 0.0663 & 7649.4 & Not realizable \\
\hline
\end{tabular}

As more bundles of hoses remain in the warehouses with associated increases in holding costs, the Total Inventory Cost also increases .This would result in the company incurring more debts. The Total Inventory Cost (TIC) often depends on the lead time demand, the expected shortage cost at the end of the period, the fraction of demand backordered during stock out period and the quantity demanded by the customers. Shortage brings loss of goodwill and it is difficult to the exact amount of shortage cost. The same problem is experienced in the case of the ordering and holding costs hence in inventory, the decision maker may allow the flexibility in the cost parameter values in order to tackle the uncertainties which always fit the real situations.

\section{CONCLUSIONS}

From the study, Mantrac Ghana Limited's inventory cost was modeled using a Retroactive Holding Cost. With the model, the optimal order quantity $Q^{*}$ which minimizes the Total Inventory Cost (TIC) was determined to be $\mathbf{4 0 9}$ units. The cycle period $\mathrm{T}$ * for the quantity $\mathrm{Q}^{*}$ to be produced per cycle is 0.2 year. Mantrac Ghana Limited could order 409 units per each order within the cycle period of 0.2 year. This would minimize the Total Inventory Cost to GHc1186.9

\section{RECOMMENDATIONS}

Based on the findings so far arrived at, in order to ensure proper inventory control at Mantrac Ghana Limited, the following recommendations are made.

- To determine optimal quantity $\mathrm{Q}^{*}$, optimal Total Inventory Cost $\left(\mathrm{TIC}^{*}\right)$ and cycle period $\mathrm{T}^{*}$, companies who own storage facilities should use Retroactive Holding Cost model.

- To sustain the inventory of Mantrac Ghana Limited, stakeholders of the company should use the Retroactive Holding Cost Model to produce the quantity $\mathrm{Q}^{*}$, of $\mathbf{4 0 9}$ units per each order within the cycle period of 0.2 year.

- There should be further study at Mantrac Ghana Limited, using another holding cost as increasing step function of the storage time, : that is: higher storage cost rates apply to storage of later periods (Incremental holding cost increase).

\section{REFERENCES}

[1]. Alfares H.K (2007). Inventory model with stock-level dependent demand rate and 
variable holding cost. International Journal of Production Economics 108 . 259-265.

[2]. Baker, R.C.and Urban, TL., 1988b. A deterministic inventory system with an inventory level dependent rate. Journal of the Operation Research Society 39 (9). 823 831.

[3]. Beltran, J.L.and Krass, D., 2002. Dynamic lot sizing with returning items and disposals. IIE Transactions 34 (5). 437 - 448.

[4]. Datta, T.K. and Pal, A. K. ( 1990). A note an inventory model with inventory level dependent rate. Journal of the Operation Research Society 41 (10). $971-975$.

[5]. Goh, M. (1992). Some results for inventory models having inventory level dependent demand rate. International Journal of Production Economics 27 (1). 155 - 160.

[6]. Größler, A. 2004. A Content and Process View on Bounded Rationality in System Dynamics. Systems Research and Behavioral Science, 21, 319-330.

[7]. Hadley, G and Whitin, T M (1963). Analysis of Inventory Systems, Prentice Hall, Inc., Englewood Cliffs, NJ.

[8]. Hwang. H., Hahn. K. H., 2000. An optimal procurement policy for items with an inventory level dependent demand rate and fixed life time. European Journal of Operation Research 127 (3), 537 - 545.

[9]. Iglehart. D., Morrey. R. C. (1972). Inventory systems with imperfect asset information. Management Science 18 (8), 388 - 394.

[10]. Kang. Y and Gershwin. S. B. (2004). Information inaccuracy in inventory systems -stock loss and stock-out. IEE Transactions $37.843-859$.

[11]. Kumar. S. Arora. S. (1992). Effects of inventory miscount and non inclusion of the lead time variability on inventory system performance. IIE Transactions 24 (2). 96 103.

[12]. Nahmias S., 1997. Production and Operation analysis, volume third edition, McGraw Hill International Editions.

[13]. Pal et al. (1993).A deterministic Inventory model for deteriorating with stock dependent demand rate. International Journal Production Economics 32 (5), 291-299.

[14]. Persona. A. Battini. D. Manzini. R. Pareschi. A. 2007. Optimal safety stock levels of subassemblies and manufacturing components International Journal of Production Economics. $110(1-2) .147$ 159.

[15]. Ray, J., Chaudhuri, K.S., 1997. An EOQ model with stock dependent demand, shortage, inflation and time discounting. International Journal of Production Economics 53 (2), 171-180

[16]. Rinehart, R.F., 1960. Effects and causes of discrepancies in supply operations. Operations Research 8 (4). 543 - 564.

[17]. Ritchken.P.and Sankar. R. 1984. The effect of estimation risk in establishing safety stock levels in an inventory model. Journal of Operational Research Society 35 (12).10911099.

[18]. Shao. Y.E., Fowler. J.W.and Runger, G.C., 2000. Determine the optimal target for a process with multiple markets and variable holding costs. International Journal of Production Economics 65 (3), 229 - 242.

[19]. Sterman, J.D., 2000. Business Dynamics. McGraw - Hill. USA.

[20]. Urban, T.L., 1995. Inventory models with the demand rate dependent on stock and shortage levels. International Journal of Production Economics 40 (1), 2 - 28.

\section{APPENDIXES}

\section{APPENDIX A DATA ON STOCK, DEMAND AND SUPPLY FROM 2006 - 2010}

TABLE A1

Data on stock, demand and supply from Jan. 2005 - Dec. 2006

\begin{tabular}{|l|l|l|l|l|l|l|}
\hline YEAR & \multicolumn{2}{l}{$\mathbf{2 0 0 5}$} & $\mathbf{2 0 0 6}$ & \multicolumn{1}{l|}{} \\
\hline MONTH & STOCK & DEMAND & SUPPLY & STOCK & DEMAND & SUPPLY \\
\hline JANUARY & 2400 & 1804 & 1804 & 3500 & 1405 & 1405 \\
\hline FEBRUARY & 2060 & 2045 & 2045 & 2600 & 1975 & 1975 \\
\hline MARCH & 2500 & 1750 & 1750 & 4000 & 4128 & 4000 \\
\hline APRIL & 1500 & 251 & 251 & 4500 & 2145 & 2145 \\
\hline MAY & 1400 & 468 & 468 & 4800 & 2694 & 2694 \\
\hline JUNE & 900 & 390 & 390 & 3000 & 1945 & 1945 \\
\hline JULY & 1000 & 1005 & 1000 & 4100 & 3056 & 3056 \\
\hline
\end{tabular}




\begin{tabular}{|l|l|l|l|l|l|l|} 
AUGUST & 2000 & 1065 & 1065 & 3500 & 2043 & 2043 \\
\hline SEPTEMBER & 935 & 50 & 50 & 1000 & 632 & 632 \\
\hline OCTOBER & 3500 & 3567 & 3500 & 2000 & 1024 & 1024 \\
\hline NOVEMBER & 4000 & 1157 & 1157 & 1200 & 380 & 380 \\
\hline DECEMBER & 3000 & 4309 & 3000 & 1500 & 1902 & 1500 \\
\hline AVERAGE & $\mathbf{2 0 9 9 . 5 8}$ & $\mathbf{1 4 8 8 . 4 2}$ & $\mathbf{1 3 7 3 . 3 3}$ & $\mathbf{2 9 7 5}$ & $\mathbf{1 9 4 4 . 0 8}$ & $\mathbf{1 8 9 9 . 9 2}$ \\
\hline
\end{tabular}

TABLE A.2 Data on stock, demand and supply from Jan. 2007 - Dec. 2008

\begin{tabular}{|l|l|l|l|l|l|l|}
\hline YEAR & \multicolumn{2}{l}{$\mathbf{2 0 0 7}$} & $\mathbf{2 0 0 8}$ \\
\hline MONTH & STOCK & DEMAND & SUPPLY & STOCK & DEMAND & SUPPLY \\
\hline JANUARY & 2400 & 1504 & 1504 & 3000 & 1704 & 1704 \\
\hline FEBRUARY & 3000 & 2040 & 2040 & 2500 & 1865 & 2500 \\
\hline MARCH & 2900 & 3400 & 2900 & 3895 & 4234 & 3895 \\
\hline APRIL & 4000 & 2100 & 2100 & 4022 & 3001 & 3001 \\
\hline MAY & 3000 & 1934 & 1934 & 3200 & 2890 & 2890 \\
\hline JUNE & 2500 & 2310 & 2310 & 3000 & 2003 & 2003 \\
\hline JULY & 3500 & 3078 & 3078 & 4300 & 3070 & 3070 \\
\hline AUGUST & 3100 & 2250 & 2250 & 3500 & 2065 & 2065 \\
\hline SEPTEMBER & 1510 & 712 & 712 & 1450 & 520 & 520 \\
\hline OCTOBER & 1200 & 500 & 500 & 1250 & 792 & 792 \\
\hline NOVEMBER & 1300 & 890 & 890 & 1000 & 450 & 450 \\
\hline DECEMBER & 2000 & 2068 & 2000 & 1500 & 1600 & 1500 \\
\hline AVERAGE & $\mathbf{2 5 3 4 . 1 7}$ & $\mathbf{1 8 9 8 . 8 3}$ & $\mathbf{1 8 5 1 . 5}$ & $\mathbf{2 7 1 8 . 0 8}$ & $\mathbf{2 0 1 6 . 1 7}$ & $\mathbf{2 0 3 2 . 5}$ \\
\hline
\end{tabular}

TABLE A.3 Data on stock, demand and supply from Jan. 2009 - Dec. 2010

\begin{tabular}{|l|l|l|l|l|l|l|}
\hline YEAR & \multicolumn{2}{l}{$\mathbf{2 0 0 9}$} & $\mathbf{2 0 1 0}$ \\
\hline MONTH & STOCK & DEMAND & SUPPLY & STOCK & DEMAND & SUPPLY \\
\hline JANUARY & 2500 & 1607 & 1607 & 3200 & 1850 & 1850 \\
\hline FEBRUARY & 2800 & 2045 & 2045 & 3400 & 2135 & 2135 \\
\hline MARCH & 3500 & 4560 & 3500 & 3500 & 3590 & 3500 \\
\hline APRIL & 5000 & 3500 & 3500 & 4000 & 3250 & 3250 \\
\hline MAY & 3400 & 2750 & 2750 & 3840 & 2850 & 2850 \\
\hline JUNE & 3000 & 1984 & 1984 & 3000 & 2000 & 2000 \\
\hline JULY & 3200 & 3055 & 3055 & 3010 & 3045 & 3010 \\
\hline AUGUST & 3100 & 2750 & 2750 & 4500 & 2800 & 2800 \\
\hline SEPTEMBER & 2500 & 810 & 810 & 3000 & 900 & 900 \\
\hline OCTOBER & 1800 & 655 & 655 & 2100 & 610 & 610 \\
\hline NOVEMBER & 1145 & 798 & 798 & 1490 & 780 & 780 \\
\hline DECEMBER & 1340 & 1400 & 1340 & 1000 & 1200 & 1000 \\
\hline AVERAGE & $\mathbf{2 7 7 3 . 7 5}$ & $\mathbf{2 1 5 9 . 5}$ & $\mathbf{2 0 6 6 . 2}$ & $\mathbf{3 0 0 3 . 3 3}$ & $\mathbf{2 0 8 4 . 1 7}$ & $\mathbf{2 0 5 7}$ \\
\hline
\end{tabular}

AVERAGE ANNUAL DEMAND (D) FOR THE PERIOD - $\quad 23182.32$ units 
AVERAGE ANNUAL STOCK

AVERAGE ANNUAL SUPPLY
32207.88 units

- $\quad \mathbf{1 8 7 5 7 . 2 6}$ units

\section{APPENDIX B}

\begin{tabular}{|l|l|}
\multicolumn{1}{|c}{ Table B1 Data on cost components } \\
\hline COST & AMOUNT (GH $\mathbf{c})$ \\
\hline Fixed ordering cost per inventory cycles $(\mathrm{C})$ & 58.00 \\
\hline Holding cost per item per year $(\mathrm{h})$ & 2.90 \\
\hline
\end{tabular}

Bernard Osei Owusu. "Determination of Optimum Quantity Cost and Cycle Time Using Inventory Model with Stock Level Dependent Demand Rate and Variable Holding Cost. (A Case Study of Mantrac Ghana Limited)." International Journal of Engineering Research and Applications (IJERA) 7.7 (2017): 55-75. 